\title{
The Novel Hyper-Combustion for the Complete Combustion of Fossil Fuels
}

\author{
Ruggero Maria Santilli
}

\begin{abstract}
The current combustion of fossil fuels is essentially the same as it was at the dawn of our civilization some fifty thousand years ago. In fact, we strike a spark and ignite the fuel, with increasingly alarming climactic changes due to the lack of complete combustion. In preceding works, the author achieved the complete combustion of the synthesized fuel known as magnegas. In this paper, we propose, apparently for the first time, new principles of combustion under the suggested name of HyperCombustion (patent pending) based on the recently achieved fusion of Carbon and Oxygen into Silicon without the release of harmful radiation, with ensuing significant increase of the energy output, the achievement of complete combustion, and the reduction of the green house gase $\mathrm{CO}_{2}$ for a given energy output.
\end{abstract}

Index Terms-Molecular combustion, magnecular combustion, hypercombustion.

\section{INTRODUCTION}

Our increasingly alarming environmental problems (see, e.g., Fig. 1) are mostly due to the current combustion [1]-[6] of commercially available fossil fuels, such as gasoline, diesel or coal, which is essentially the same as it was at the dawn of our civilization some fifty thousand years ago. In fact, we essentially strike a spark and ignite the fuel, resulting in the release of excessive contaminants.

In this paper, we outline the studies on combustion by the author initiated in the late 1970's while he was at Harvard University under support from the Department of Energy [7]-[72] and propose, apparently for the first time, basically new principles of combustion here submitted under the name of HyperCombustion ${ }^{T M}$ (patent pending) which aims at the achievement (in due time and following due investments) of a complete combustion of fossil fuels, hereon referred to as a combustion without combustible contaminants in the exhaust.

For this task, we identify in Section II the features of conventional combustion that are responsible for the indicated environmental problems; we then outline in Section 3 the novel magnecular combustion that has already achieved the indicated complete combustion for the gaseous fuel magnegas; we introduce in Section IV the principles and available experimental evidence of HyperCombustion offering realistic possibilities of extending to fossil fuels the complete combustion already achieved by magnegas; and we close the paper with expected environmental implications of

Manuscript received November 9, 2018; revised January 28, 2019.

Ruggero Maria Santilli is with the National Institute of Standards and Technology, Boulder, CO 80305 USA (e-mail: research@thunder-energies.com).
HyperCombustion and open problems.

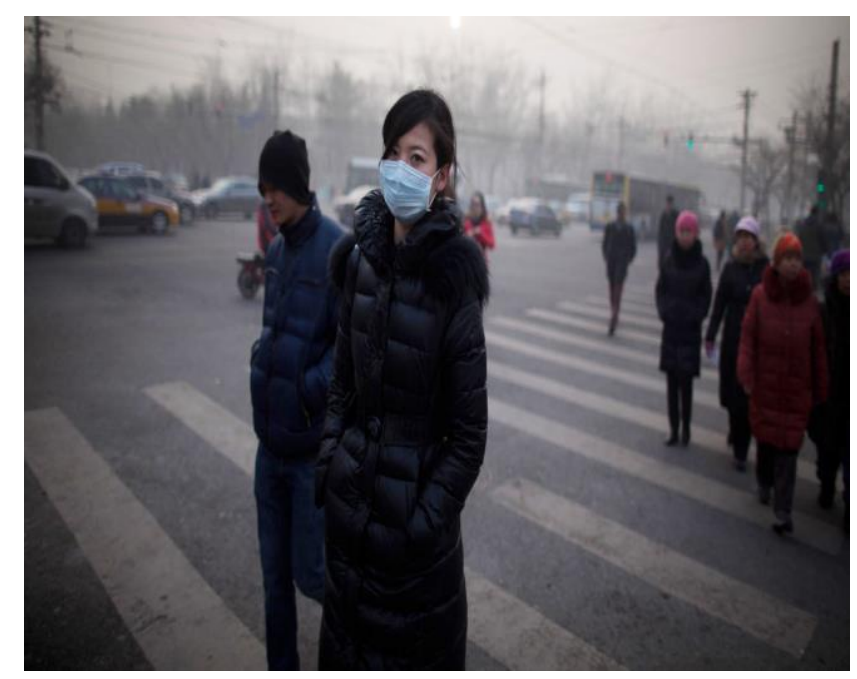

Fig. 1. A view of the atmospheric pollution in Beijing, China, on a sunny day.

\section{Molecular Combustion}

The terms molecular combustion are hereon referred to as the current combustion of fuels with conventional molecular structure (Fig. 2), thus being composed by atoms such as carbon $\mathrm{C}$, hydrogen $\mathrm{H}$ and other elements bonded together by the conventional valence bond (alternatively called covalence bond) which is hereon indicated with the symbol “-." Well known examples (see Refs. [1]-[5] are given by the combustion of hydrogen and oxygen]

$$
H-H+\frac{1}{2} \mathrm{O}-\mathrm{O} \rightarrow \mathrm{H}-\mathrm{O}-\mathrm{H}+57.5 \mathrm{kcal} / \mathrm{mol} .
$$

that of carbon and oxygen symbol

$$
\mathrm{C}+\frac{1}{2} \mathrm{O}-\mathrm{O} \rightarrow \mathrm{CO}+25 \mathrm{kcal} / \mathrm{mole}
$$

and others [1]-[6].

Note that, according to our definition, combustion (1) is "complete" (because $\mathrm{H}_{2} \mathrm{O}$ is not combustible), while combustion (2) is "incomplete" (because $\mathrm{CO}$ is combustible). In this study, we also assume, for simplicity, that we have the perfect stochiometric ratio between fuel and oxygen to prevent the incompleteness of otherwise complete reactions, such as (1).

In the author's view and experience, despite advances that are clearly historical [6], the achievement of a full combustion of commercially available fossil fuels requires the identification and resolution of the following open 
problems of quantum chemistry with particular reference to its treatment of combustion (see, e.g., Section II of Ref. [16]):

2.1. The 20th century notion of "valence bond" is merely conceptual due to the lack of a quantitative identification of the bonding force because two identical valence electrons must repel, and certainly not attract each other according to quantum mechanics and chemistry since they have the same charge. The ensuing lack of a quantitative representation of the "molecules." then clearly prevents basic advances in the combustion of fossil fuels.

2.2. As it is well known, all combustions are irreversible over time, while quantum mechanics and chemistry are strictly reversible over time from their axioms and dynamical equations. Consequently, quantum mechanics and chemistry are only approximately valid for a quantitative treatment of combustion. The lack of axiomatically and dynamically correct formulations for irreversible chemical reactions is an evident additional limitation for the improvement of combustion since it does not allow reliable theoretical predictions.

2.3. Due to their local-differential mathematical structure, quantum mechanics and chemistry can only represent energy releasing chemical reactions as occurring in between point-like molecules solely under action-at-a-distance potential interactions. In fact, said theories cannot represent non-linear, non-local and non-potential interactions expected in all energy releasing processes, which broader interactions were assumed by Lagrange and Hamilton to be necessary for the representation of nature and were represented via external terms in their celebrated equations that are absent in 20th century sciences.

Additiionally, despite a century of studies, we remain with ambiguities in the presentation and treatment of the energy released by basic combustions, such as (1) [2]-[4] whose resolution, as we shall see, is important for the achievement of the complete combustion of fossil fuels. Consider, as an example, the widespread statement that combustion (1) produces $57.5 \mathrm{kcal} / \mathrm{mole}$. However, as evident from the structure of water $H-O-H$, a necessary condition for combustion (1) is that the hydrogen and oxygen "molecules" are separated into "atoms" requiring $104.2 \mathrm{kcal} / \mathrm{mole}$ and $119.1 / 2=59.5 \mathrm{kcal} / \mathrm{mole}$. Consequently, in order not to violate the conservation of energy, the energy output of combustion (1) should be

$$
\begin{aligned}
& 104.2_{\text {Hsep }}+59.5_{\text {Osep }}+57.5=163.7_{\text {mp-sep }}+57.5= \\
& 221.2 \text { Kcal/mole } \backslash
\end{aligned}
$$

The author initiated his studies of the complete combustion of fossil fuels with the first and only known quantitative identification of attractive force in valence coupling thanks to the prior construction of the novel isomathematics [7]-[9] for the representation of non-linear, non-local and non-Hamiltonian interactions in total mutual penetrations of wavepackets, with ensuing isomechanics [10], [11] and isochemistry [12]. The resulting attractive valence force, known as Santilli isovalence bond [p.12], resulted to be so strong to overcome the repulsive Coulomb force as well as permit the first known exact representation of the binding energies and other data of the hydrogen [13] and water [14] molecule.

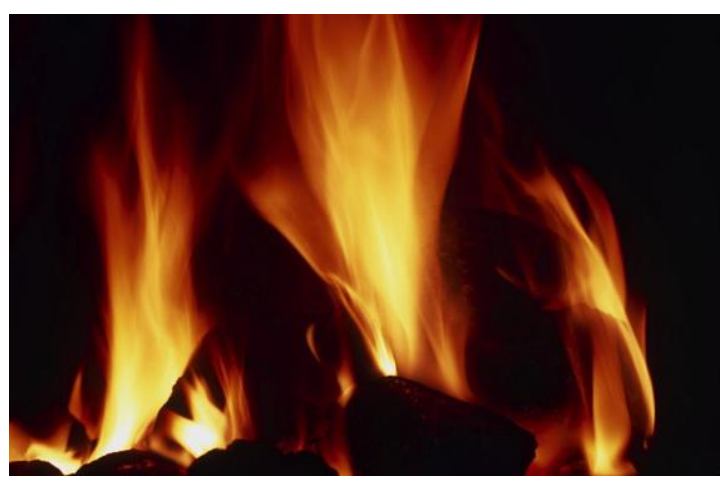

Fig. 2. An illustration of the fact that the current combustion of fossil fuels is the same as it was at the dawn of civilization.

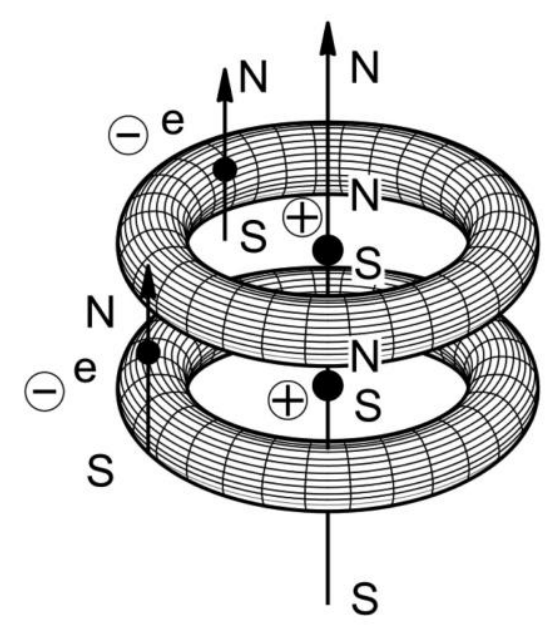

Fig. 3. A view of the basic magnecule between Carbon and Oxygen which is at the basis of the new combustion.

Despite the achievement of an attractive valence force, isoformulations remained reversible over time in both their axioms and dynamical equations because it is necessary to represent the reversibility over time of isolated molecules. In order to achieve a resolution of irreversible chemical reactions, the author had no other choice than to build broader formulations for the vresolution of insufficiencies 2.1, 2.2 and 2.3, including the covering genomathematics [7]-[9] embedding irreversibility in the most basic operations, such as ordered products and units, with ensuing genomechanics [10], [11] and genochemistry [12]. The axiomatic and dynamical consistency of the broader genoformulations was proved in Refs. [15], [16].

Unfortunately, we have no possibility of even outlining these above isotopic and genotopic formulations to prevent a prohibitive length. Nevertheless, their knowledge is essential for a true understanding of the HyperCombustion presented in Section IV. A recent general review by the author is provided in Sections II and III of Ref. [16], independent studies are available from monographs [17]-[20], while a general independent review is available in Ref. [21].

\section{Magnecular COMBUStion}

According to the studies outlined in the preceding sections, the inability of commercially available fossil fuels to achieve a complete combustion is due to: the strength of valence bonds that cannot be entirely broken under the released energies; the combustion temperature which is insufficient to 
infinite combustible contaminants in the exhaust; and otherfactors.

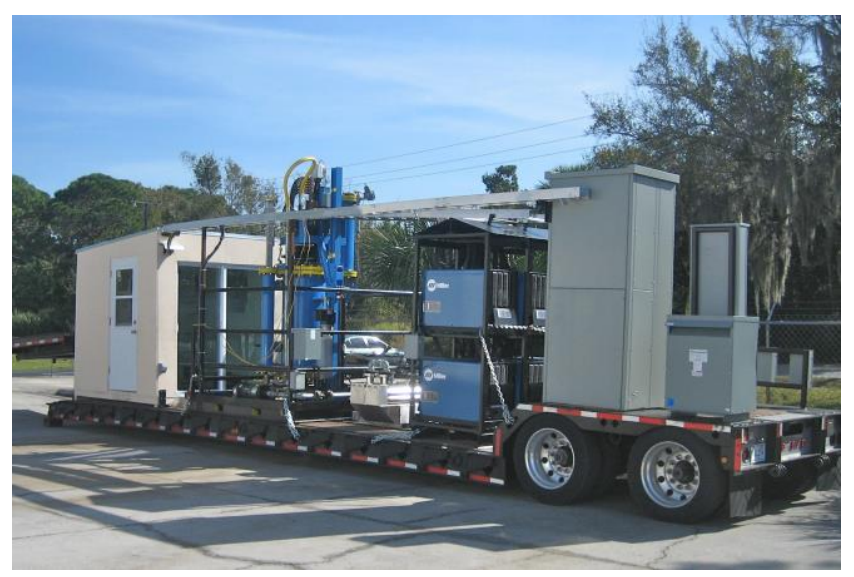

Fig. 4. view of the gasifiers built by the author when Chief Scientist of Magnegas Corporation converting liquids into the clean burning magnegas fuel.

Following, and only following, the identification of the actual attractive force in valence bonds a related quantitative representation of molecular structures [7]-[12], the author initiated in the 1990's the search of means to weaken valence bonds because in the evident hope of improving the currently available combustions. Following a number of unpublished trials and errors, the author had no other choice than that of working out a new chemical species with a bond weaker than the valence bond.

Following a decade of research, the author reported in Ref. [22] of 1998 (see also the comprehensive treatment in monograph [21] of 2001) mathematical, theoretical and experimental evidence suggesting the existence of a new chemical species structurally different than that of molecule, today known as Santilli magnecules [21] which consists of atoms $\mathrm{H}, \mathrm{C}$, O, etc., dimers $\mathrm{C}-\mathrm{H}, \mathrm{H}-\mathrm{O}$, etc, and ordinary molecules $\mathrm{H}-\mathrm{H}, \mathrm{C}-\mathrm{O}$, etc. bonded together by opposing polarities of toroid configurations of atomic electrons achieved under suitably strong magnetic fields [23] (see Figure 3 for a view of the "elementary magnecule").

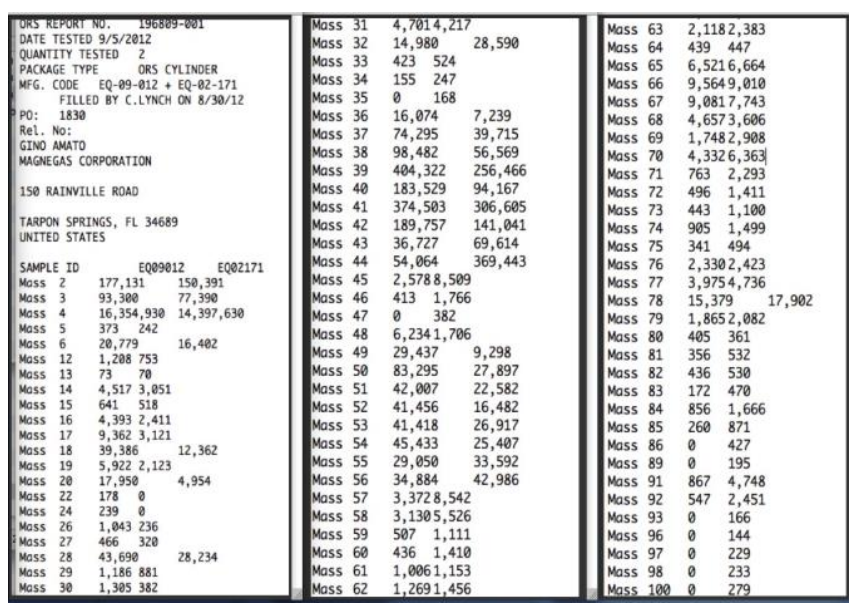

Fig. 5. Reproduction of a certified chemical analysis of magnegas showing the presence of constituents from 2 to hundreds of amu.

From 2007 to 2012, in his capacity of Chief Scientist of the publicly traded company Magnegas Corporation (www.magnegas.com), the author constructed reactors (see an example in Fig. 4) converting liquids into a gaseous fuel known as magnegas. Since the gasification process was done via a submerged DC electric arc, it had to have the necessary strength for the toroid polarization of atomic electrons. Said polarizations evidently disappear at the disconnection of the arc. Nevertheless, pairs of polarized and coupled atoms as in Fig. 4 retain their bond at ambient temperature, thus having the stability necessary for industrial applications. In this way, the author identified a number of fuels with a magnecular structure covered by U. S. Patent 9,700,870, B2 [24], including: magnegas (MG) [25]; magnehydrogen (MH) and magneoxygen (MO) [26]; a new gaseous form of water (HHO) [27]; and other magnecular gases [28].

According to the above studies, under condition of polarization MG is composed by a collection of magnecules here referred to as clusters with magnecular bonds of all atoms, hereon denoted " $x$ " that can be symbolically represented with the structure

$M G=\{H \times H+H-H \times H+H \times H \times H+C-O \times H+$

The above chemical structure has been confirmed by various tests, such as the measurements conducted at ONEIDA Research Services of Whitesboro, New York, via methods.
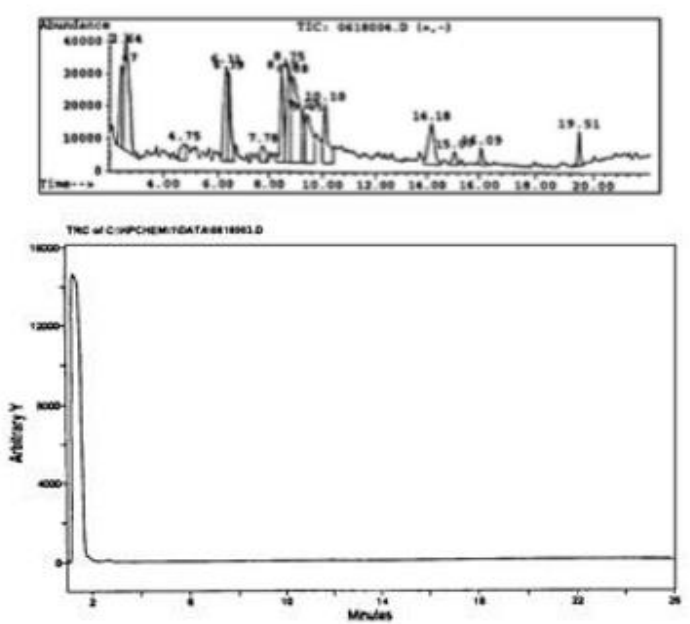

Fig. 6. A view of the first experimental detection of magnecules showing in the top the clusters obtained via a gas chromatographer, mass spectrometer and in the bottom the lack of detection via an infrared detector thus confirming that the former cannot be molecules.

ORS SOP MEL-1070: Gas Analysis [29] (see Fig. 5 for a summary). These measurements show that MG is composed by clusters from 2 to $200 \mathrm{amu}$, of course, with different concentrations, thus confirming magnecular structure (4). Note that measurements [29] (Fig. 5) cannot be credibly explained by assuming that MG has a conventional molecular structure.

In addition to the original experimental evidence presented in the author's proposal [12], [22], the existence of magnecules has been confirmed by a number of independent tests [30]-[33] (see also Refs. [34]-[28]). These detections generally turned out to be of difficult understanding by laboratory analysts because they attempt the detection of the new chemical species of magnecules with equipment, such as gas chromatographer mass spectrometers (GC-MS), that has been specifically designed for molecules. This is due to the 
fact that magnecules have a bond estimated to be $1 / 10$ th that of a molecule. As a consequence, ionization means in GC-MS that are so effective for the detection of molecule, generally destroys the magnecular species they have to detect, reduce them to their conventional molecular components, thus showing the apparent lack of new species.

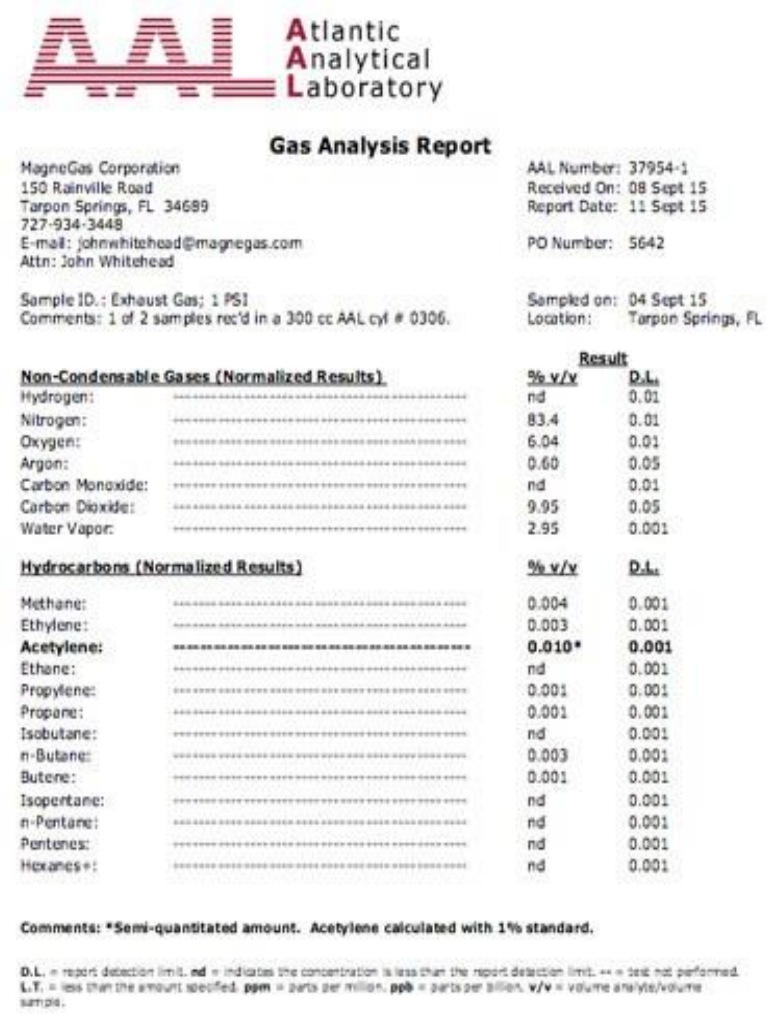

Fig. 7. Chemical analysis of magnegas exhaust by Atlantic Analytic Laboratories showing the absence of carbon monoxide (as ND) and small traces of hydrocarbons.

Since new detectors specifically designed for magnecules are not available at the moment, the only known experimental detection of magnecules remains that of original proposal [22], consisting in an indirect detection via the use of a GC-MS equipped with an infrared detector (GC-MS/IRD). The same sample of gas is first inspected in the GC-MS operated at the minimal possible temperature, ionization energy and other settings, resulting in the identification of the clusters composing the gas. The same sample is then analyzed with the IRD. In the event the IRD confirms the existence of the clusters from the identified by the GC-MS (top view) had a signature under the IRD, thus prohibiting the clusters in the GC-MS to have a molecular structure. Note that $\mathrm{CO}_{2}$ is detected in the IRD (Bottom left of Fig. 6) but not present in the GC-MS detections (top of Fig. 6), thus establishing that $\mathrm{CO}_{2}$ is a constituent of the magnecular clusters. All subsequent detections [30]-[38] essentially provide a confirmation of said original detections.

GC-MS at their amu, said clusters are conventional molecules. By contrast, in the event the IRD shows no signature at the amu values of the GC-MS clusters, said clusters cannot possibly be molecules due to their lack of resonating frequency. In Fig. 6 we reproduce the original detections of Ref. [22]. As one can see, none of the clusters

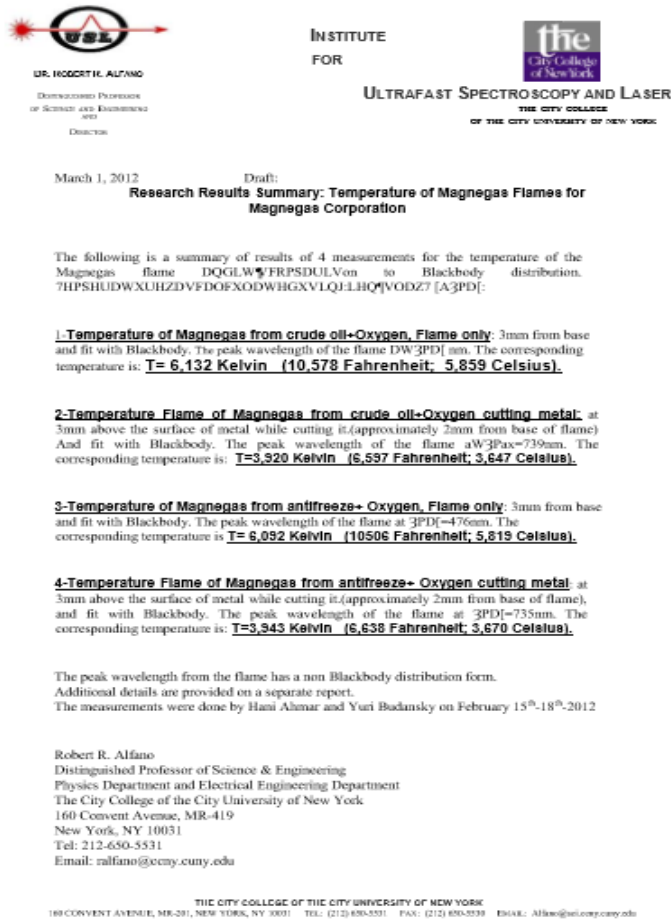

Fig. 8. Spectroscopic analysis of magnegas flame showing a temperature which is about three times that of any other commercially available fue.

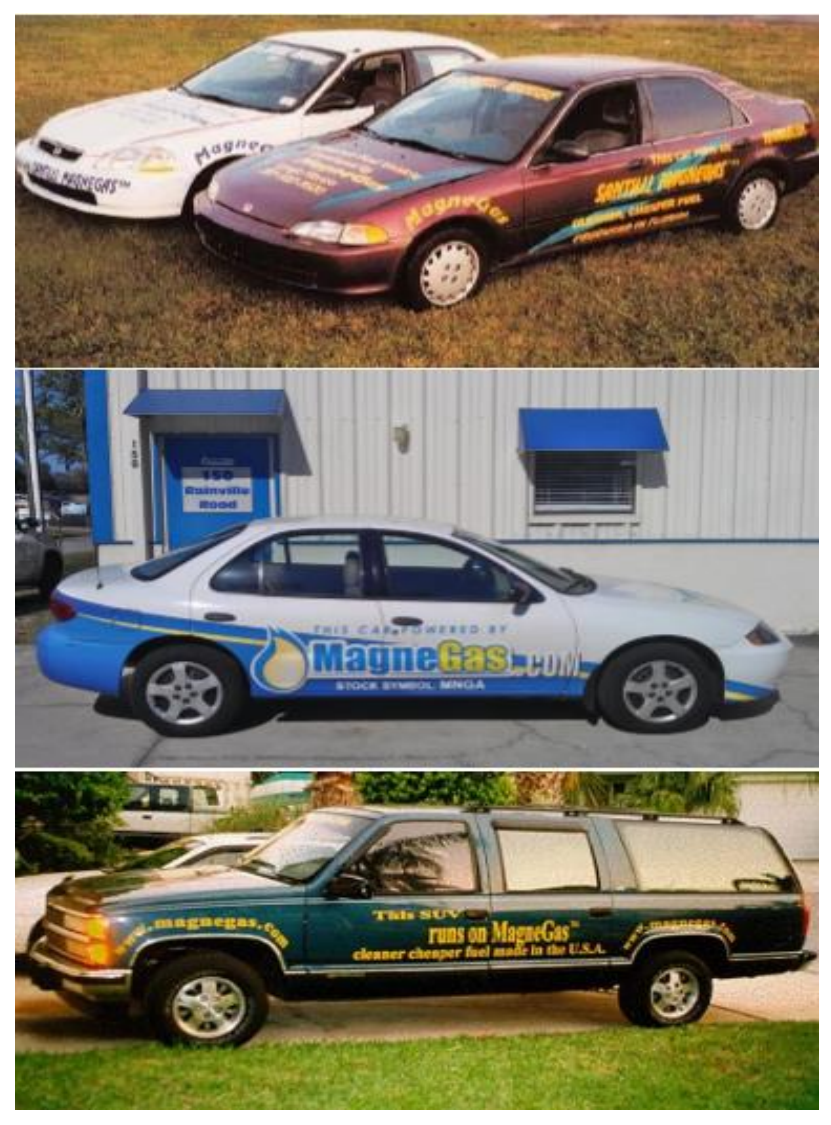

Fig. 9. A view of stock cars operated by the author with magnegas without catalytic converter wssing EPA requirements due to the quality of the exhaust shown in Figurehile surpa 7.

The interested reader should be informed that, since the date of Ref. [22] (1998), GCMS and IRD detectors have considerably increased the rapidity of the analyses evidently via the increase of the ionization energy and other advances. While such increases have no effect for magnecules, they 
evidently decrease the capability of identifying magnecular clusters. In fact, the original detections of magnecules were done via the analytic laboratories of McClellan Air Force Base near Sacramento, CA, via a GC-MS/IRD comprising of a HP GC model 5890, a HP MS model 5972 and a HP IRD model 5965. During the independent tests [30]-[33], the analysts failed to reproduce with modern GC-MS the cluster of MG identified so clearly with the indicated GC-MS, again due to the excessive increase of the ionization energy and other settings in contemporary GC-MS, thus forcing the experimentalists to recondition an old HP GC model 5890, a HP MS model 5972 and a HP IRD model 5965.

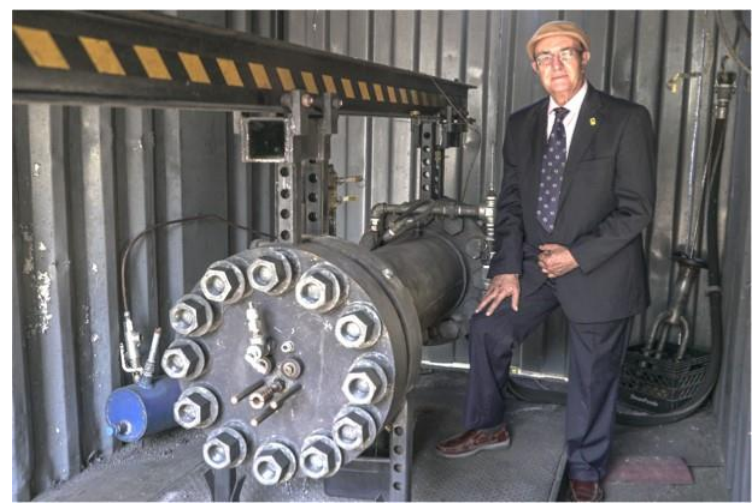

Fig. 10. View of ta prototype of the new hyperfurnaces.

A first feature of magnegas which is important for environmental aspects is that, as typically the case for all magnetic effects and related Curie Temperature, magnecular bonds disappear at combustion, thus preventing the loss of separation energies of type (3), with ensuing enhancement of energy output. In fact, MG cuts metal faster than acetylene with 2,400 BTU/scf, while having a nominal 320 $B T U / s c f$ according to standard GC-MS calculations.

The second environmentally important feature of magnegas is that, according to measurements conducted by the Ultra-Fast Spectroscopic Laboratory of the City College of New York [39], [40], the flame temperature of magnegas is also three times the flame temperature of commercially available fuels, including fossil fuels (see the summary table of Fig. 7.

The third environmentally important feature is that, under the correct stochiometric ration and MDS Ignition System, magnegas does indeed achieve complete combustion. In fact, according to analyses conducted by Atlantic Analytic Laboratories [41], the combustion of magnegas in air under correct stochiometric ratio MG.O)2 and ignition, shows no detectable $\mathrm{CO}$ and no appreciable $\mathrm{HC}$ (see the summary table in Fig. 8). Needless to say, under an improper stochiometric system or insufficient voltage or energy of the ignition, magnegas combustion cannot be complete.

In view of the above features, when he was Chief Scientist of Magnegas Corporation, the author was driving various stock cars produced to run on natural gas (NG) but operated with MG. These cars surpassed all EPA regulations without catalytic converters. Note that the above three anomalies establish the magnecular structure of magnegas since the same anomalies admit no quantitative representation via the conventional molecular species.

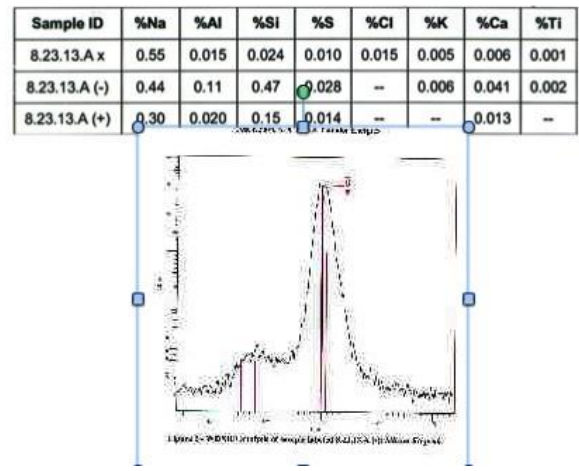

Fig. 11. A view of the certified analysis by Constellation Laboratories s establishing experimental evidence of the central process of the new hypercombustion, I.e., the nuclear fusion of Carbon-12 and Oxygen-16 into Silicon-28.

The above results signaled the achievement by the author of the intended environmental advance. Therefore, the author left Magnegas Corporation for the U. S., publicly traded company Thunder Energies Corporation for the extension of the above results to fossil fuels as described in the next section.

\section{HYPERCOMBUSTION}

In this section we submit, apparently for the first time, the possible extension of the complete combustion of magnecular fuels of Section III to commercially available fossil fuels (such as gasoline, diesel or coal) under the name of HyperCombustion, (patent pending) via the following main new principles:

PRINCIPLE 4,1: Ignite fossil fuels with a series of rapid DC discharges, each having at least $100 \mathrm{kV}$ and at least $100 \mathrm{~J}$, hereon called HyperSparks.

PRINCIPLE 4.2: Convert fossil fuels from their natural molecular structure to a magnecular form,

PRINCIPLE 4,3: Enhance the combustion temperature, magnecular conversion and the energy output vie the fusion of Carbon-12 and Oxygen-16 into Silicon-28

$C(6,12,0,12.0000000)++O(8,16,0,15.9949146) \rightarrow$

$\operatorname{Si}(14,28,0,27.9769265)$

$\Delta E=0,0179881$ amu $=16.75591515 \mathrm{MeV} / \mathrm{c}^{2}$

as well as other nuclear fusions, engineered according to the laws of Intermediate Controlled Nuclear Fusions (ICNF) without the emission of harmful radiations and without the release of radioactive waste (see Refs. [42]-[51] for theoretical treatments, Refs. [52]-[60] for independent studies, Refs. [61]-[72] for laboratory report, and Ref. [49] for the synthesis of Silicon, Fig. 10 for an ICNF reactor, Ref. [50] for a DVD on its operation, and Ref. [51] for its sound).

Principle 4,1 is crucial for the achievement of a combustion temperature necessary for a complete combustion as well as for molecular separation and atomic ionization, and from the triggering of ICNF. Principle 4.2, which can be also engineered the highly efficient magnegas reactors, is crucial for the reduction of energy lost in molecular separation, e.g., the lost energy of 163.7 $\mathrm{Kcal} / \mathrm{mole}$ of Eq. (3). Principle 4.3 is crucial for the 
enhancement of all preceding processes, as well as for he increase of the energy output compared to that of conventional combustion of the same fuel.

The equipment implementing the above principles is here submitted under the name of HyperFurnaces (see Figure 10 for a prototype and Ref. [50], [51] for short DVD on its operation). In its expected industrial realization, HyperFurnaces are expected to include ceramic realization of the hadronic reactors of IUCNF essentially converting the correct mixture of fossil fuel and air into a high temperature exhaust without combustible contaminants via a number of equipment including: computerized stochiometric ration of fuel and air; exchangers for the desired use of the heath, such as for household radiators or electric generators; a processing station for cooled down exhaust prior to its release in the environment; and overall shield for electromagnetic and other radiations; and other equipment.

Special $R \& D$ is recommended for the station treating the exhaust for its safe release to the environment. Said exhaust is expected to contain primarily $\mathrm{CO}_{2}$, but also other inert gases as well as solid particulates. The current, increasingly alarming environmental changes suggest the investment of all the necessary funds for the development of such a processing station via molecular separation or the processes so that no harmful gas is released in appreciable quantities.

It is evident that the production of the greenhouse gas $\mathrm{CO}_{2}$ increases under complete combustion due to the combustion of $\mathrm{CO}, \mathrm{HC}$ and other contaminants. However, the percentage of $\mathrm{CO}_{2}$ per energy output is considerably decreased in HyperFurnaces due to the fusion of C-12 and O-16 into Si-28 that produce no $\mathrm{CO}_{2}$ (see Ref. [49] and Fig. 11).

\section{CONCLUDING REMARKS}

In this paper we have submitted, apparently for the first time, a basically new combustion under the suggested name of HyperCombustion, essentially consisting in the enhancement of the energy output of fossil fuels combustion via the fusion of C-12 and O-16 into Si-28 without harmful radiation, which fusion has been recently achieved via the hadronic reactors (see Fig. 10 for a prototype) of Intermediate Controlled Nuclear Fusions (ICNF) (see Refs. [7]-[72] in general, Ref. [49] in particular, and Fig. 11 for a summary of independent measurements).

In case funding is made available for its proper development, HyperCombustion would achieve a complete combustion of fossil fuels with a significant reduction of our current environmental problems. Since ICNF releases no contaminants in the environment, HyperCombustion would additionally achieve a significant reduction of the green house gas $\mathrm{CO}_{2}$ for a given energy output compared to their current combustion with the same energy output. The additional problem of $\mathrm{CO}_{2}$ separation and recycling in an environmentally acceptable form, which is expected to mandate investments of the order of billions of dollars, has been identified but not addressed in this paper because requiring separate studies.

In closing, let us recall the lack of achievement of new clean nuclear or other energies in the past seventy years of research despite the use of bllions of dollars of public funds. The studies reported in this paper [7]-[72] establish that our alarming environmental problems cannot be solved with 20th century sciences, and require basically new mathematics, physics and chemistry.

This is due to the fact that 20th century sciences, including Einstein's theories, quantum mechanics and quantum chemistry, were conceived for, and are solely applicable to systems reversible over time (such as the hydrogen atom, particles in accelerators, etc.), while all energy releasing processes are irreversible over time, in addition to other structural insufficiencies (Section II) requiring the surpassing of 20th century theories in favor of suitable covering theories.

Therefore, in the author's view and experience, the inability by our society to solve alarming environmental problems is primarily due to the suppression of scientific democracy for qualified inquiries orchestrated by the academic-governmental complex.

\section{ACKNOWLEDGMENTS}

The author has no words to express his appreciation to Anil A. Bhalekar, Ascar Aringazin, and Simone Beghella Bartoli for important critical comments and suggestions. Additional thanks are due to Carla Santilli and Sherri Stone for the linguistic control of the manuscript.

\section{REFERENCES}

[1] I. Glassmann and R. A. Yetter, Combustion, Academic Press, 2008.

[2] B. deB. Darwent, "Bond dissociation Energies in simple molecules," U. S. department of Commerce, 1970.

[3] F. D. Rossini, The Heat of Formation of Water, Proc. N.A.S., vol. 16, pp. $694-699,1930$

[4] A. A. Frost and R. G. Pearson, Kinetics and Mechanism, John Wiley and and Sons, Inc., New York and London, second ed. (1961).

[5] L. M. Das, "Hydrogen-oxygen reaction mechanism and its implicati ton to hydrogen engine combustion," Int. J. Hydrogen Energy, vol. 21, no. 8, pp. 703-715, 1996.

[6] A. Szabo and N. S. Ostlund, Modern Quantum Chemistry: Introduction to Advanced Electronic Structure Theory, Springer, 2012.

[7] R. M. Santilli, Foundation of Theoretical Mechanics, Volume I [3a] (1978) and II [3b] (1982) Springer-Verlag, Heidelberg, Germany. [Online]. http://www.santilli-foundation.org/docs/Santilli-209.pdf http://www.santilli-foundation.org/docs/santilli-69.pdf

[8] R. M. Santilli. (1993). Isonumbers and genonumbers of dimensions 1, 2, 4, 8, their isoduals and pseudoduals, and 'Hidden Numbers' of dimension 3, 5, 6, 7, algebras, groups and geometries. [Online]. 10(273). Available: http://www.santilli-foundation.org/docs/Santilli-34.pdf

[9] R. M. Santilli. (1996). Nonlocal-Integral Isotopies of Differential Calculus, Mechanics and Geometries. in Isotopies of Contemporary Mathematical Structures, Rendiconti Circolo Matematico Palermo. Suppl. [Online]. 42(7-82) Available: http://www.santilli-foundation.org/docs/Santilli-37.pdf

[10] R. M. Santilli. (1995). Elements of Hadronic Mechanics, Vol. I and Vol. II [15b], Academy of Sciences, Kiev. http://www.santilli-foundation.org/docs/Santilli-300.pdf http://www.santilli-foundation.org/docs/Santilli-301.pdf

[11] R. M. Santilli (2008). Hadronic mathematics, mechanics and chemistry. International Academic Press, [Online]. 1-5. Available: http://www.i-b-r.org/Hadronic-Mechanics.htm

[12] R. M. Santilli, Foundations of Hadronic Chemistry, with Applications to New Clean Energies and Fuels, Kluwer Academic Publishers (2001). http: //www.santilli-foundation.org/docs/Santilli-113.pdf Russian translation by A. K. Aringazin http://i-b-r.org/docs/Santilli-Hadronic-Chemistry.pdf

[13] R. M. Santilli and D. D. Shillady,, "A new isochemical model of the hydrogen molecule," Intern. J. Hydrogen Energy Vol. 24, pages 


\section{3-956}

http://www.santilli-foundation.org/docs/Santilli-135.pdf

(1999)

[14] R. M. Santilli and D. D. Shillady, "A new isochemical model of the water molecule," Intern. J. Hydrogen Energy, vol. 25, pp. 173-183 () http://www.santilli-foundation.org/docs/Santilli-39.pdf, 2000.

[15] R. M. Santilli, "Lie-admissible invariant representation of irreversibility for matter and antimatter at the classical and operator levels," Nuovo Cimento B 121, 443(2006), http://www.santilli-foundation.org/docs//Lie-admiss-NCB-I.pdf

[16] R. M. Santilli, “An introduction to new sciences for a new era," In press at Clifford Analysis, Clifford Algebras and their Applications, December 2016 (Cambridge,U.K http://www.santilli-foundation.org/docs/new-sciences-new-era.pdf

[17] Chun-Xuan Jiang, Foundations of Santilli Isonumber Theory, International Academic Press (2001) http://www.i-b-r.org/docs/jiang.pdf

[18] D. S. Sourlas and G. T. Tsagas, Mathematical Foundation of the Lie-Santilli Theory, Ukraine Academy of Sciences (1993). http://www.santilli-foundation.org/docs/santilli-70.pdf

[19] Raul M. Falcon Ganfornina and Juan Nunez Valdes, Fundamentos de la Isdotopia de Santilli, International Academic Press (2001). http://www.i-b-r.org/docs/spanish.pdfEnglish translations Algebras, Groups and Geometries Vol. 32, pages 135-308(2015). http://www.i-b-r.org/docs/Aversa-translation.pdf

[20] S. Georgiev, Foundations of the IsoDifferential Calculus, Volumes, I, II, III, IV, V, and VI Nova Scientific Publisher (2015 on).

[21] I. Gandzha and J. Kadeisvili, New Sciences for a New Era: Mathematical, Physical and Chemical Discoveries of Ruggero Maria Santilli, Sankata Printing Press, Nepal (2011), http://www.santilli-foundation.org/docs/RMS.pdf

[22] R. M. Santilli, "Theoretical prediction and experimental verification of the new chemical species of magnecules," Hadronic J. 21, 789 (1998),"http://www.santilli-foundation.org/docs/Santilli-43.pd

[23] A. K. Aringazin, "Toroidal configuration of the orbit of the electron of the hydrogen atom under strong external magnetic fields," Hadronic J. 24 134 http://www.santilli-foundation.org/docs/magnegas-combustion.pdf

[24] . M. Santilli, "Method and Apparatus for the industrial production of new hydrogen-rich fuels,: United States Patent Number 9,700,870, B2, July

2017 http://www.santilli-foundation.org/docs/Magnecule-patent.pdf

[25] 2. R.M. Santilli and A.K. Aringazin, "Structure and Combustion of Magnegases", Hadronic J. 27 (2004) 299-330. physics/0112066. http://www.santilli-foundation.org/docs/combustion

[26] R. M. Santilli, "The novel magnecular species of hydrogen and oxygen with increased specific weight and energy content," Intern. J. Hydrogen

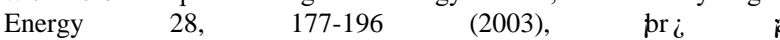
href="http://www.santilli-foundation.org/docs/Santilli38.pdf" ¿http:// www.santilli-foundation.org/docs/Santilli-38.pdf $; / a_{i j} b_{i}{ }_{i} p_{i}$

[27] R. M. Santilli, "A new gaseous and combustible form of water," Intern. J. Hydrogen Energy 31, 1113 (2006), http://www.santilli-foundation.org/docs/Santilli-138.pdf

[28] R. M. Santilli, The New Fuels with Magnecular Structure, International Academic

(2008)http://www.i-b-r.org/docs/Fuels-Magnecular-Structure.pdfItalia $\mathrm{n}$ translation by Giovanna Bonfanti and Michele Sacerdoti, Editori Riuniti, Roma, Italy, and available at I Nuovi Carburanti con Struttura Magnecolare http://www.i-b-r.org/docs/nuopvi-carburanti-magnecolari.pdf

[29] D. Rossiter, Director, "IVA Report 200010 on comparative Nitrogen counts.

http://www.santilli-foundation.org/docs/Oneida-analyses-2013.zip

[30] Y. Yang, J. V. Kadeisvili, and S. Marton, "Experimental Confirmations of the New Chemical Species of Santilli Magnecules," The Open Physical Chemistry JournalVol. 5, 1-16 (2013),http://www.santilli-foundation.org/docs/Magnecules-2012.pdf

[31] Day D. TCD analysis and density measurements of Santilli Magnehydrogen. Eprida Laboratory report dated 11/10/11

http://www.santilli-foundation.org/docs/Eprida-MH-Certification-1011.pdf

[32] Y. Yang, J. V. Kadeisvili, and S. Marton, "Experimental Confirmations of the New Chemical Species of Santilli MagneHydrogen," International Journal Hydrogen Energy Vol. 38, page 5002 (2013); bri ¡ahref="http://www.santillifoundation.org/docs/MagneHydrogen-201 2.pdf” ¿http://www.santillifoundation.org/docs/MagneHydrogen-2012. $\operatorname{pdf}_{i} / a_{i} ; b_{i} i p_{i}$

[33] Vijay M. Tangde, "Advances in hadronic chemistry and its applications," Foundation of Chemistry, DOI 10.1007/s10698-015-9218-z (March 24, 2015), http://www.santilli-foundation.org/docs/hadronic-chemistry-FC.pdf

[34] S. P. Zodape, "The MagneHydrogen in HadronicChemistry,"AIP Proceedings 1558, 648 (2013); doi: 10.1063/1.4825575; bri http://www.santillifoundation.org/docs/sangesh-Greece.pdf

[35] C. P. Pandhurnekar, "Advances on Alternative Fuels with Santilli Magnecular Structure," International Journal of Alternative Fuels, ISSN: $\quad 2051-5987, \quad$ Vol.17, 2015 http://www.santilli-foundation.org/docs/Magnegas-2015.pdf

[36] S. P. Zodape, "Novel Chemical Species of Santilli's Magnegas," AIP Proceedings 1648, 510022 (2015); doi: 10.1063/1.4912727, http://www.santilli-foundation.org/docs/1.4912727(SP-Zodape).pdf

[37] S. S. Wazalwar, V. M. Tangde and A. A. Bhaleka, "Study of Combustion of Coal with Magnegas as Additive for Improved Combustion Efficiency: A Review of Present Scenario and Future Scope," AIP Conference Proceedings 1648, 510021 (2015); doi: $10.1063 / 1.4912726$; bri href="http://www.santilli-foundation.org/docs/1.4912726(WazalwarTangdeBhalekar).pdf" ¿http://www.santilli-foundation.org/docs/1.491 2726(WazalwarTangde-Bhalekar).pdf ${ }_{i} / a_{i j} b_{i} r_{i} p_{i}$

[38] Sangesh P. Zodape, "Novel Chemical Species of Santilli's Magnegas in Hadronic Chemistry," AIP Conference Proceedings 1648, 510022 (2015); doi: 10.1063/1.4912727; br $\underset{i}{ } \quad$ ia href="http://www.santillifoundation.org/docs/1.4912727(SP-Zodape). pdf" ¿http://www.santillifoundation.org/docs/1.4912727(SP-Zodape).p $\mathrm{df}_{i} / \mathrm{a}_{i} ; \mathrm{br}_{i} ; \mathrm{p}_{i}$

[39] R. R. Alfano, "CCNY Certification of Magnegas Flame Temperature," Summary, http://thunder-energies.com/docs/Magnegas-flame

[40] R. R. Alfano, "CCNY Certification of Magnegas Flame Temperature," Report, http://thunder-energies.com/docs/MG-Flame-report.pdf

[41] R. F. Frisch, "Chemical analysis of magnegas exhaust," http://thunder-energies.com/docs/MG-AAL-comnustion-analyses.pdf

[42] R. M. Santilli, "A quantitative isotopic representation of the deuteron magnetic moment," in Proceedings of the International Symposium 'Dubna Deuteron-93, Joint Institute for Nuclear Research, Dubna, Russia (1994) http://www.santilli-foundation.org/docs/Santilli-134.pdf

[43] R. M. Santilli, "Nuclear realization of hadronic mechanics and the exact representation of nuclear magnetic moments," R. M. Santilli, Intern. J. of Phys. Vol. 4, 1-70(1998) http://www.santilli-foundation.org/docs/Santilli-07.pdf

[44] A. A. Bhalekar and R. M. Santilli, "Exact and Invariant Representation of Nuclear Magnetic Moments and Spins According to Hadronic Mechanics," American Journal of Modern Physics, 2016; 5(2-1): 56-118 http://www.santilli-foundation.org/docs/nuclear-MM-spins.pdf

[45] R. M. Santilli. "The novel "Controlled Intermediate Nuclear Fusion:" A report on its industrial realization as predicted by hadronic mechanics," Hadronic J. 31, 1,2008 http://www.i-b-r.org/CNF-printed.pdf

[46] R. Brenna, T. Kuliczkowski, L. Ying, "Verification of Santilli intermediate Controlled Nuclear Fusions without harmful radiations a and the production of magnecular clusters," New Advances in Physics, 5, 9 (2011) http://www.santilli-foundation.org/docs/ICNF-2.pdf

[47] J. V. , C. Lynch and Y. Yang, "Confirmations of Santilli Intermediate Nuclear Fusions of Deuteron and Carbon into Nitrogen without Radiations." The Open Physical Chemistry HJournal 5, 172013 http://www.santilli-foundation.org/docs/ICNF-Conf-2013.pdf

[48] R. M. Santilli, "Experimentally evidence on the synthesis of Silicon from Oxygen and Carbon without harmful radiation or waste," Proceedings of the Third International Conference on the Lie-Admissible Treatment of Irreversible Processes, $; / i_{i}$ Kathmandu University (2011) pages 163-177 http://www.santillifoundation.org/docs/ICNF-4.pdf

[49] ] R. M. Santilli, Additional Confirmation of the Intermediate Controlled Nuclear Fusions without harmful radiation or waste, iProceedings of the Third International Conference on the Lie-Admissible Treatment of Irreversible Processes,/i Kathmandu University (2011) pages 189-202 http://www.santilli-foundation.org/docs/ICNF-3.pdf

[50] R. M. Santilli, 10 minutes DVD on the "Operation of the Hadronic Reactor III for the synthesis the Silicon (download the file and open with DVD software) http://www.world-lecture-series.org/dragon-iii

[51] R. M. Santilli, The sound of Intermediate Controlled Nuclear Fusions (download the file and open with VLC or equivalent)www.santilli-foundation.org/Thunder-Fusions.amr 
[52] U. Abundo, "Interpretation $\mathrm{n}$ and enhancement of the excess energy of Rossi's reactor via Santilli neutroids and nucleoids," Hadronic Journal Vol. 37, pages 697-737(2014, pdf link $106 \mathrm{MB}$

http://www.thunder-fusion.com/docs/abundo-paper-2014.pdf

[53] J. V., C. Lynch and Y. Yang, Confirmations of Santilli Intermediate Nuclear Fusions of Deuteron and Carbon into Nitrogen without Radiations. The Open Physical Chemistry HJournal 5, 172013 http://www.santilli-foundation.org/docs/ICNF-Conf-2013.pdf

[54] . Ying, W. Cai, J. , C. Lynch, S. Marton, S. Elliot and Y. Yang, Experimental verification for Intermediate Controlled Nuclear Fusion, City College of New York Preprint, to appear, http://www.santilli-foundation.org/docs/ICNF-Cai-paper- Ying.pdf

[55] Leong Ying, Verification of Santilli Intermediate Nuclear Harmful Radiation and the Production of Magnecular C

[56] Leong Ying, Verification of Santilli Intermediate Nuclear Harmful Radiation and the Production of Magnecular Clusters, Lecture VD of the website http://www.world-lecture-series.org/level-v

[57] R. B. Lanjewar, A Brief Review of Intermediate Controlled Nuclear Syntheses (ICNS) without Harmful Radiations AIP Conference Proceedings 1648, 510012(2015); doi: 10.1063/1.4912717 http://www.santilli-foundation.org/docs/1.4912717(RB-Lanjewar).pdf

[58] Chandrakant S. Burande,, "On the Rutherford-Santilli Neutron Model" AIP Conference Proceedings 1648, 510006 (2015); doi: $10.1063 / 1.4912711$

http://www.santilli-foundation.org/docs/1.4912711(CS-Burande(1)).p df

[59] Indrani B. Das Sarma. "Hadronic Nuclear Energy: An Approach Towards Green Energy," AIP Conference Proceedings 1648, 510008 (2015); doi: 10.1063/1.4912713 http://www.santilli-foundation.org/docs/1.4912713(IB-Das Sarma).pdf

[60] Sudhakar S. Dhondge, "Santilli's Hadronic Mechanics of Formation of Deuteron," AIP Conference Proceedings 1648, 510009 (2015); doi: 10.1063/1.4912714 http://www.santilli-foundation.org/docs/1.4912714(SS-Dhondge).pdf

[61] D. Rossiter, Director, IVA Report 184443 on comparative Nitrogen counts (for Ref. [78]), www.santilli-foundation.org/docs/IVAReport-184443.pdf

[62] D. Rossiter, Director, IVA Report 184445 on comparative Nitrogen counts on samples of the Nitrogen synthesis, www.santillifoundation.org/docs/Spectral-analysis-Ref-[79].png

[63] R. Brenna, T. Kuliczkowski and L. Ying, Report on Test for Silicon on the Nitrogen synthesis http://www.santilli-foundation.org/docs/PGTI-Anal-test1.pdf

[64] D. Rossiter, Director, IVA Report 189920 on comparative Silica counts, www.santilli-foundation.org/docs/IVAReport 189920.pdf
[65] D. Rossiter, Director, IVA Report 189920 on comparative Silica counts, oxygen synthesis. www.santillifoundation.org/docs/IVAReport 189920.pdf

[66] D. Rossiter, Director, IVA Report 200010 on comparative Nitrogen counts. http://www.santilli-foundation.org/docs/Oneida-analyses2013.zip

[67] R. Brenna, T. Kuliczkowski, L. Ying, Verification of Santilli intermediate Controlled Nuclear Fusions without harmful radiations a and the production of magnecular clusters, New Advances in Physics, 5, 9 (2011) http://www.santilli-foundation.org/docs/ICNF-2.pdf

[68] D. Swartz, Constellation Technologies first report on comparative Silica counts, http://www.santilli-foundation.org/docs/Constellation-Si-10-13.zip

[69] D. Swartz, Constellation technologies second report on comparative Silica counts, http://www.santilli-foundation.org/docs/Constellation-Rep-Si- 2.zip

[70] D. Swartz, Constellation technologies Third report on comparative Silica counts, http://www.santilli-foundation.org/docs/Constell-Si-3.pdf

[71] A. Nas, Data on Constellation technologies tests 1 and 2 on comparative Silica counts,

http://www.santilli-foundation.org/docs/Data-Constelltests. docx

[72] D. Swartz, Constellation technologies Third report on comparative Silica counts, http://www.santilli-foundation.org/docs/Constell-Silicon-10-14.pdf

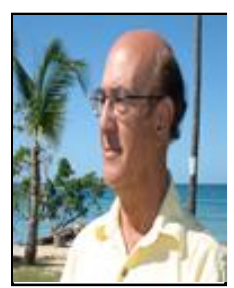

Ruggero M. Santilli obtained his $\mathrm{Ph}$. D. from the University of Torino, Italy; he then and emigrated to the U.S.A. where he was in the faculty of the University of Miami, Boston University, MIT, and Harvard University under financial support from NASA, UFOSR and DOE; he is the author of 325 papers published in refereed journals and twenty post $\mathrm{Ph}$. D. monographs in mathematics, physics and chemistry; he is internationally known for the discovery of hadronic mathematics, physics, and chemistry and their applications to new clean energies; that have been the subject of over 50 international conferences; he is the editor of numerous scientific journals. Since 2002, Prof. Santilli is the founder and chief scientist of two U. S.publicly traded companies Magnegas Corporation (stock symbol MNGA) and Thunder Energies Corporation ( stock symbol TRNRG) developing cutting edge new technologies; he has received numerous awards including the 2007 Mediterranean Prize, and has been knighted twice with the title of Sir, a first time by the republic of San Marino in 2011 and a second time by the President of Italy, Sergio Mattarella, in June 2018. For details, please see the Biographica

http://www.i-b-r.org/Dr-R-M-Santilli-Bio-1-10-18.pd
Notes 